\title{
Anatomical Distribution of the Growth-Associated Protein GAP-43/B-50 in the Adult Rat Brain
}

\author{
Larry I. Benowitz, ${ }^{1,2,4}$ Paul J. Apostolides, ${ }^{1}$ Nora Perrone-Bizzozero, ${ }^{1,2}$ Seth P. Finklestein, ${ }^{1,3,5}$ and Henk \\ Zwiers $^{6}$ \\ 'Mailman Research Center, McLean Hospital, Belmont, Massachusetts 02178, Departments of ${ }^{2}$ Psychiatry and ${ }^{3}$ Neurology \\ and ${ }^{4}$ Program in Neuroscience, Harvard Medical School, Boston, Massachusetts 02115, ${ }^{5}$ Department of Neurology, \\ Massachusetts General Hospital, Boston, Massachusetts 02114, and 'Departments of Medical Physiology/Medical \\ Biochemistry, University of Calgary, Calgary, Alberta, Canada
}

\begin{abstract}
GAP-43 (B-50, F 1, pp46) is a neuron-specific phosphoprotein that has been implicated in the development and modulation of synaptic relationships. Although most neurons cease expressing high levels of GAP-43 after the completion of synaptogenesis (Jacobson et al., 1986), certain brain regions continue to have considerable amounts of the protein throughout life (Oestreicher et al., 1986); in at least one such area, the phosphorylation of the protein has been linked with the events that underlie synaptic potentiation (Lovinger et al., 1985). In this study, we used the indirect immunoperoxidase method to map the distribution of GAP-43/B-50 in the brains of 8 adult rats with 2 different antibodies: a monospecific, polyclonal antibody prepared in sheep against the purified protein and an affinity-purified IgG prepared in rabbits. Specific immunoreactivity was found primarily in the neuropil and followed a generally increasing caudal-to-rostral gradient along the neuraxis. Densest staining occurred in layer I of the cortex, the CA1 field of the hippocampus, and in a continuum of subcortical structures that included the caudate-putamen, olfactory tubercle, nucleus accumbens, bed nucleus of the stria terminalis, amygdala, and medial preoptic area-hypothalamus. In the brain stem, staining was seen in the central gray and in ascending visceral relay nuclei, but was essentially absent in areas related to ascending somatosensory information (e.g., the cochlear nuclei or vestibular complex) and motor control (e.g., nucleus ruber or the motor nuclei of the cranial nerves). Staining in dorsal thalamus was likewise modest in most somatosensory and somatomotor relay nuclei, but dark in certain other structures (e.g., mediodorsal nucleus, lateral complex). This distributional pattern raises the question of whether synapses in all areas containing high levels of GAP-43/B-50 are
\end{abstract}

\footnotetext{
Received May 7, 1987; accepted July 14, 1987.

This work was supported by grants from the National Eye Institute (NIH EY05690), a BRSG grant from the NIH (RR05484), a grant-in-aid from the American Heart Association (with funds contributed in part by its Virginia affiliate), and by funds from the Marion Benton Trust of McLean Hospital. H.Z. is a scholar of the Alberta Heritage Foundation for Medical Research. We are grateful to Gary Conboy for instruction in immunohistochemical methods, Martha Shea for typing the manuscript, Ken Moya for assistance in preliminary studies, Dr. G. E. Schneider for helpful comments, Dr. Nigel Fleming of Polyclonal Sera Labs (Cambridge, MA) for helping to raise the antibodies in sheep, and David Ko and Jody Houston for preparing the affinity-purified antibody in rabbit.

Correspondence should be addressed to Larry I. Benowitz at the above address. Copyright (c) 1988 Society for Neuroscience $0270-6474 / 88 / 010339-14 \$ 02.00 / 0$
}

capable of undergoing functional plasticity, or whether the protein may function in some of these areas in some other capacity (e.g., general signal transduction).

GAP-43 (B-50, F1, pp46) is a neuron-specific phosphoprotein that appears to play a role in the development and functional modulation of synaptic relationships. During development, GAP-43 is one of a small number of proteins that is expressed selectively in association with process outgrowth (Perrone-Bizzozero et al., 1986); its synthesis and axonal transport persist at high levels throughout axogenesis and synaptogenesis, and then decline precipitously with the establishment of stable synaptic relationships (Benowitz et al., 1981; Skene and Willard, $1981 \mathrm{a}, \mathrm{b}$; Benowitz and Lewis, 1983; Freeman et al., 1986; Kalil and Skene, 1986; Moya et al., 1987; Perry et al., 1987). GAP43 is conveyed in the rapid phase of axonal transport from the neuronal somata in which it is synthesized to the nerve terminals (Benowitz et al., 1981; Skene and Willard, 1981a, b; Benowitz. and Lewis, 1983), where it is enriched in the membranes of growth cones and of developing synapses (De Graan et al., 1985; Katz et al., 1985; Meiri et al., 1986; Skene et al., 1986).

Throughout the rat brain as a whole, levels of GAP-43 are highest during the first postnatal week, a period in which synaptic organization is still taking place, then fall by more than $90 \%$ over the next few weeks (Jacobson et al., 1986). However, the fact that appreciable levels persist in the mature CNS, and the recent realization that this protein is identical to the phosphoprotein B-50 (Jacobson et al., 1986; Perrone-Bizzozero et al., 1986; Zwiers et al., 1987) or Fl (Nelson et al., 1985), which has been described in adult presynaptic membranes, suggest that GAP-43 continues to play a role in the functioning of certain synapses throughout life.

Previous studies on the role of ACTH in CNS functioning had led to the identification of the cognate protein B-50 as a prominent ACTH- and $\mathrm{Ca}^{2+}$-dependent phosphoprotein of the mature synaptic membrane (Zwiers et al., 1976, 1978). B-50 was subsequently shown to be a neuron-specific substrate of protein kinase $C$ that may regulate phosphotidylinositol metabolism, and hence the generation of secondary and tertiary messengers at the synapse (Jolles et al., 1980; Zwiers et al., 1980; Aloyo et al., 1982; Van Dongen et al., 1985). This same protein was identified in another context as phosphoprotein F1 (Routtenberg and Ehrlich, 1974; Nelson and Routtenberg, 1985), and has recently been implicated in the physiological events that 
underlie long-term potentiation (LTP). In the hippocampus of the adult rat, the phosphorylation of Fl correlates highly with the degree of LTP that results from high-frequency stimulation of the perforant pathway (Akers and Routtenberg, 1985; Lovinger et al, 1985). LTP in this pathway, and presumably the increased phosphorylation of GAP-43 (F1), may result from a translocation of protein kinase $\mathrm{C}$ from the cytosolic compartment to the presynaptic membrane as a consequence of the highfrcquency stimulation (Akers and Routtenberg, 1985; Malenka et al., 1986).

Radioimmune assays have shown that in the brain of the adult rat, levels of B-50 are highest in the cerebral cortex, septum, and hippocampus, and low in cerebellum and medulla (Oestreicher et al., 1986); this distribution is consistent with the results of an earlier study on total B-50 phosphorylation in different brain areas (Kristjansson et al., 1982). More detailed studies using immunocytochemistry have identified areas within the rat hippocampus and cerebellum that show specific B-50 immunoreactivity, and have demonstrated striking changes in the developmental pattern of the proteins' distribution in these regions (Oestreicher and Gispen, 1986). To date, however, there exists no complete description of the distribution of this protein throughout the brain.

In view of the possibility that GAP-43 (B-50, F1) may serve an important function in the adult ncrvous system related to synaptic plasticity (Routtenberg, 1985; Pfenninger, 1986), we have examined the anatomical distribution of this protein in the adult rat brain in detail using immunocytochemistry. The results of our study demonstrate a complex pattern of GAP-43 immunoreactivity, with highest concentrations in the neuropil of limbic and integrative areas at more rostral levels of the neuraxis.

\section{Materials and Methods}

Six adult male and 2 adult female Sprague-Dawley rats (250-300 gm; Charles River Laboratories, Wilmington, MA) were anesthetized with pentobarbital and perfused transcardially with $100 \mathrm{ml}$ of $0.1 \mathrm{M} \mathrm{PBS} \mathrm{(pH}$ 7.6), followed immediately by $400 \mathrm{ml}$ cold $4 \%$ paraformaldehyde (either with $0.2 \%$ glutaraldehyde-GTA $-n=4$ males, 2 females, or without GTA) in $0.1 \mathrm{~m}$ phosphate buffer $(\mathrm{pH} 7.6)$. The length of exposure to the fixative during perfusion was $15-20 \mathrm{~min}$, followed by $2 \mathrm{hr}$ to $6 \mathrm{~d}$ postfixation at $4^{\circ} \mathrm{C}$. Brains were then transferred to $30 \%$ sucrose in 0.1 M PBS ( $\mathrm{pH} \mathrm{7.6)} \mathrm{for} \mathrm{cryoprotection.}$

Thirty-five micron coronal sections (from 6 rats) or parasagittal sections, cut on the freezing stage of a sliding microtome, were collected in phosphate buffer. Series of free-floating sections (at c. $420 \mu \mathrm{m}$ spacing) were preincubated for $30 \mathrm{~min}$ in $0.01 \% \mathrm{H}_{2} \mathrm{O}_{2}$ in methanol, and then for $1 \mathrm{hr}$ in blocking buffer [20\% nonimmune rabbit or goat scrum in PBS containing $0.3 \%$ Triton X-100 (PBST) (Sigma)]. Sections were then reacted $1-3 \mathrm{~d}$ in varying concentrations of primary antibody $(1 / 500$ $1 / 20,000$ ) in PBST plus $1 \%$ serum plus $0.3 \%$ azide at $4^{\circ} \mathrm{C}$. Antibody staining was revealed by using the avidin-biotin complex method of peroxidase labeling (Hsu et al, 1981; Vector Laboratories, Burlingame, CA). Briefly, sections were rinsed in PBST/serum, incubated for $1 \mathrm{hr}$ in either biotinylated rabbit anti-sheep or goat anti-rabbit immunoglobulins (secondary antibody), rinsed again, and incubated for $1 \mathrm{hr}$ in avidin-biotin-peroxidase complex (Hsu et al., 1981). The peroxidase label was revealed by using diaminobenzidine (DAB) (Sigma; $0.05 \%$ in $50 \mathrm{~mm}$ Tris, pH 7.6) with $0.01 \% \mathrm{H}_{2} \mathrm{O}_{2}$ for 3-5 min. Sections were rinsed several times in Tris buffer prior to mounting.

Antibodies. Sections were reacted with 2 different antibody preparations, one an antiscrum (or the IgG fraction alone) prepared in sheep against pure rat GAP/B-50, and the other an affinity-purified antibody against the same protein prepared in rabbit. Three different nonimmune sheep sera, including one from an animal subsequently immunized against GAP-43, served as controls. To raise the first antibody, 2-3 mg of electrophoretically pure GAP-43/B-50 was prepared from c. $50 \mathrm{gm}$ wet weight rat brain as described (Benowitz et al., 1987). In brief, we fol- lowed steps $1-5$ of the alkaline extraction procedure described by Zwiers et al. (1985) for B-50, then used a 2-stage separation on a high-performance liquid chromatography (HPLC) size-exclusion column; under these nondetergent conditions, GAP/B-50 elutes at $>90 \%$ purity as part of a high-molecular-weight complex most likely consisting of 4 identical subunits, each having an apparent molecular weight $\left(M_{\mathrm{r}}\right)$ on SDS-polyacrylamide gels of $48 \mathrm{kDa}$, and a true size closer to $30 \mathrm{kDa}$ (Benowitz et al., 1987). Final purification of the HPLC column eluate was achieved by preparative electrophoresis. Approximately $2 \mathrm{mg}$ of the purified protein was used by Polyclonal Sera Labs (Cambridge, MA) to inoculate a sheep 3 times over an 8 week period. At concentrations of 1:150 and 1:1500, serum obtained 3 weeks after the final inoculation reacted specifically with a single band $\left(M_{\mathrm{r}} 48 \mathrm{kDa}\right)$ on Western blots of total rat brain proteins (Fig. 1, $a, b$ ). On a 2-dimensional Western blot of proteins from the synaptosomal plasma membrane fraction (in which the protein is enriched), the protein recognized by the antiserum is seen unequivocally to be GAP-43 $\left(M_{\mathrm{r}} 48 \mathrm{kDa}\right.$, pI 4.7 ; Fig. $1 d$ ). Two further purification steps of the antibody included isolation of the $\mathrm{IgG}$ fraction and affinity-purifying anti-GAP IgGs. To obtain the IgG fraction, whole serum was passed over an Affi-Gel CM blue column (Bio-Rad, Richmond, CA, according to the manufacturer's specifications), and the eluate, containing the immunoglobulins, was precipitated with ammonium sulfate $(0-45 \%)$. The IgG fraction was reconstituted in PBS (plus $0.1 \% \mathrm{NaN}_{3}$ ) to the starting volume of the serum. To further purify anti-GAP-43 IgGs, c. $200 \mu \mathrm{g}$ of electrophoretically purified GAP-43/ B-50 (prepared as above) was transferred to a nitrocellulose filter and used to affinity-purify specific IgGs from whole serum, as described by Goldstein et al. (1986). The eluate from these membranes reacted specifically with GAP-43/B-50 on a Western blot of total rat brain protein, although the titer was low $(1 / 30)$.

A second antibody used to stain tissue was prepared in rabbits against purified GAP-43/B-50 and then affinity-purified on a B-50 column as described (Oestreicher et al., 1983). This antibody reacted at a $1 / 1000$ dilution exclusively with GAP-43/B-50 on a Western blot of a gel containing the total complement of proteins in the rat brain (Fig. 2). Total IgG fraction from the same rabbit, used as a control, showed no crossreaction with B-50 prior to being immunized (not shown).

Controls included the substitution of each of 3 nonimmune sheep sera for the primary antibody, omission of the primary antibody, and preabsorbing out anti-GAP IgGs from the total sheep antiserum using a $10^{2}-10^{3}$-fold excess of purified protein.

Sections were mounted onto chrom-alum-gelatin-coated slides and in some cases counterstained lightly with cresyl violet.

\section{Results}

As described above, both antibodies used in this study showed a high degree of specificity and sensitivity to GAP-43/B-50 on Western blots. When these antibodies were used at high dilutions to stain aldehyde-fixed, free-floating tissue sections, immunostaining ranged from being completely absent in most fiber tracts and in certain areas of neuropil to being extremely dense. Throughout the brain, neuronal somata were unstained, and often stood out against dense background immunoreactivity in the neuropil (Fig. 3).

In parasagittal scctions through the rat brain, GAP immunoreactivity showed a generally increasing gradient going from the caudal hindbrain up through the forebrain (Fig. $4, A-C$ ). In the pons and medulla, the dorsal column nuclei of the ascending somatosensory pathways, nuclei cuneatis, and gracilis ( $\mathrm{Gr}$, Fig. $4 A$ ) were completely devoid of staining, as were the vestibular nuclei (MVe, SuVe, SpVe, LVe, Fig. 4, $A-C$ ), and primary and secondary auditory centers (dorsal cochlear nucleus, DC; trapezoid body, Tz; medial and lateral superior olive, MSO and LSO; and the lateral lemniscal nuclei, LLD and LLV). Intense staining was seen, however, in the nucleus solitarius (Sol, Fig. $4, A, B)$ of the medulla, the medial and lateral parabrachial nuclei (LPB, Fig. $4 C$ ) of the isthmus, and in the periaqueductal central gray (CG, Fig. 4, A, B) at all levels of the brain stem. The cerebellum, including the deep nuclei, was essentially un- 


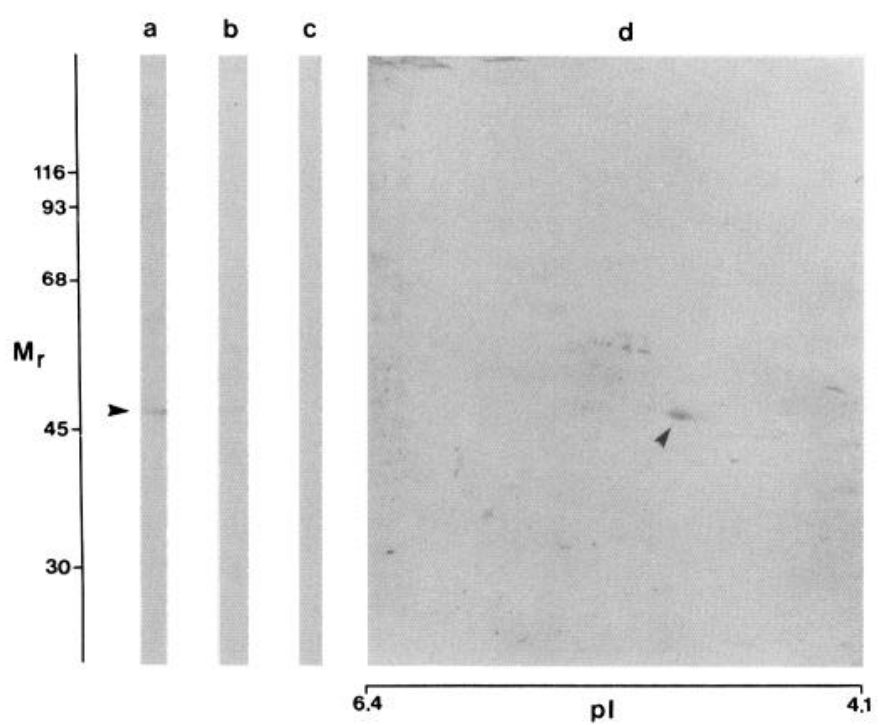

Figure 1. Specificity of the sheep anti-GAP-43 antibody. $a, b, c$, Total protein from the immature rat brain was separated on $10 \%$ polyacrylamide-SDS gels and the proteins transferred to nitrocellulose membranes (in the presence of detergent; Meiri et al., 1986). Following a blocking step in $20 \%$ BSA, blots were reacted with $(a)$ sheep anti-GAP antibody at $1 / 150$ dilution, $(b)$ the same antibody at $1 / 1500$, or $(c)$ neutral sheep serum $(1 / 1500)$. Binding of the primary antibody was visualized using a rabbit anti-sheep IgG conjugated to alkaline phosphatase and 5-bromo-4-chloro-3-indolyl phosphate as a chromagen (Knecht and Diamond, 1984). The immune, but not the nonimmune, serum reacted uniquely with a protein having an apparent molecular weight of $48 \mathrm{kDa}$, as expected for GAP-43 (B-50, F1). $d$, On Western blots of a 2-dimensional gel, on which proteins from the adult brain synaptosomal plasma membrane (SPM) fraction were separated, the 48 $\mathrm{kDa}$ protein recognized by the sheep antiserum (at $1 / 2500$ dilution) is seen to have the isoelectric point (ca. 4.7) and charge heterogeneity characteristic of GAP-43.

reactive, with the exception of light staining in outer portions of the molecular layer (Fig. 4, $A-E$ ). In the mesencephalon, both the superior colliculus (SuG, Op, Fig. 4, B, C) and inferior colliculus (IC) showed only modest staining, as did deeper structures. As was seen at lower levels, the central gray of the mesencephalon was heavily stained. The anterior pretectal nucleus (AP, Figs. $4 C, 5 D$ ) was unstained. Dense staining was seen in the medial aspect of the substantia nigra pars reticulata (SNR, Figs. $4 C, 5 D$ ), while the lateral part of this nucleus, along with the zona compacta and the ventral tegmental area (VTA, Fig. $4 B$ ), were only modestly stained.

Striking regional variations were evident in the diencephalon. As shown in both the parasagittal and coronal series (Figs. 4 and 5 , respectively), the heaviest staining in the dorsal thalamus was seen in a number of nuclei related to integrative and limbic areas of cortex, including the mediodorsal nucleus (MD, Fig. 4, $A$, $B$; particularly the medial division, MDM, Fig. 5C), the interanteromedial, interomediodorsal, and anteromedial (AM, Fig. $4 B$ ) nuclei, nuclei paraventricularis anterior (PVA, Figs. $4 A, 5 B$ ) and posterior, lateralis posterior (LP, Fig. $5 D$ ), the posterior complex (Po, Figs. $4 C, 5 C$ ), lateralis dorsalis (LD, Figs. $4 C, 5 C$ ), and reuniens ( $\mathrm{Re}, \mathrm{Fig} .4 A$ ). Staining in most nuclei related to primary sensory or motor areas of cortex, including the dorsal lateral geniculate (DLG, Fig. 5D), medial geniculate (MG, Figs. $4 D, 5 D$ ), and most of the ventral complex (VL, VM, VPM, VPL, Figs. $4, C, D ; 5 C$ ) was light. Moderately dark staining was seen, however, in the ascending relays of nociceptive
12

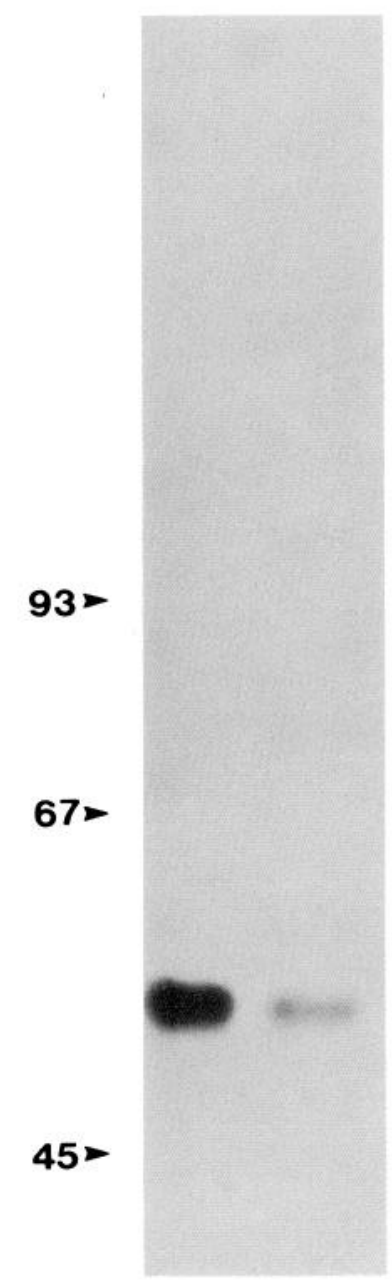

Figure 2. Specificity of the rabbit anti-GAP-43 antibody. The polyclonal antiserum, raised in rabbits against pure GAP-43 (B-50), was affinity-purified on a B-50 column as described (Oestreicher et al., 1983). At a 1/100 dilution, the antibody showed a strong reaction on Western blots to (l) $0.5 \mu \mathrm{g}$ of purified GAP- 43 (separated on an $8 \%$ polyacrylamide-SDS gel) and (2) the same protein from a lane containing $30 \mu \mathrm{g}$ of protein from the adult rat brain SPM fraction.

and special viscerosensory information, nucleus gelatinosus ( $G$, Fig. $4 B$ ), and the gustatory nucleus (Gu, Fig. $4 B$ ), respectively.

In the hypothalamus-preoptic area continuum, dense staining was observed in many periventricular and medial areas, including the medial preoptic area (MPA, Figs. $4, A, B ; 5 B$ ), the periventricular and paraventricular nuclei, the posteromedial (PMV, Fig. 4B), medial tuberal and arcuate (Arc, Fig. 5C) nuclei, the dorsomedial (DM, Fig. $4 B$ ) nucleus and the shell around the ventromedial nucleus ( $\mathrm{VMH}$, Fig. $4 B$ ), the region of the tuber cinereum (TC, Figs. $4 B, 5 C$ ), and the supramammillary nucleus.

Rostrally, intense immunoreactivity continued up through much of the basal forebrain, parts of which showed the densest staining in the brain. The bed nucleus of the stria terminalis (BST, Figs. $4 B, 5 B$ ) showed heavy staining throughout. This, in turn, was continuous with dense immunoreactivity in the substantia innominata (SI, Fig. 4, $C, D$ ), the nucleus accumbens (Acb, Fig. 4, B, C), particularly the core area (AcbC, $5 A$ ), the caudate-putamen $(\mathrm{CPu}$, Figs. $4, C, D ; 5, A, B)$, including the 


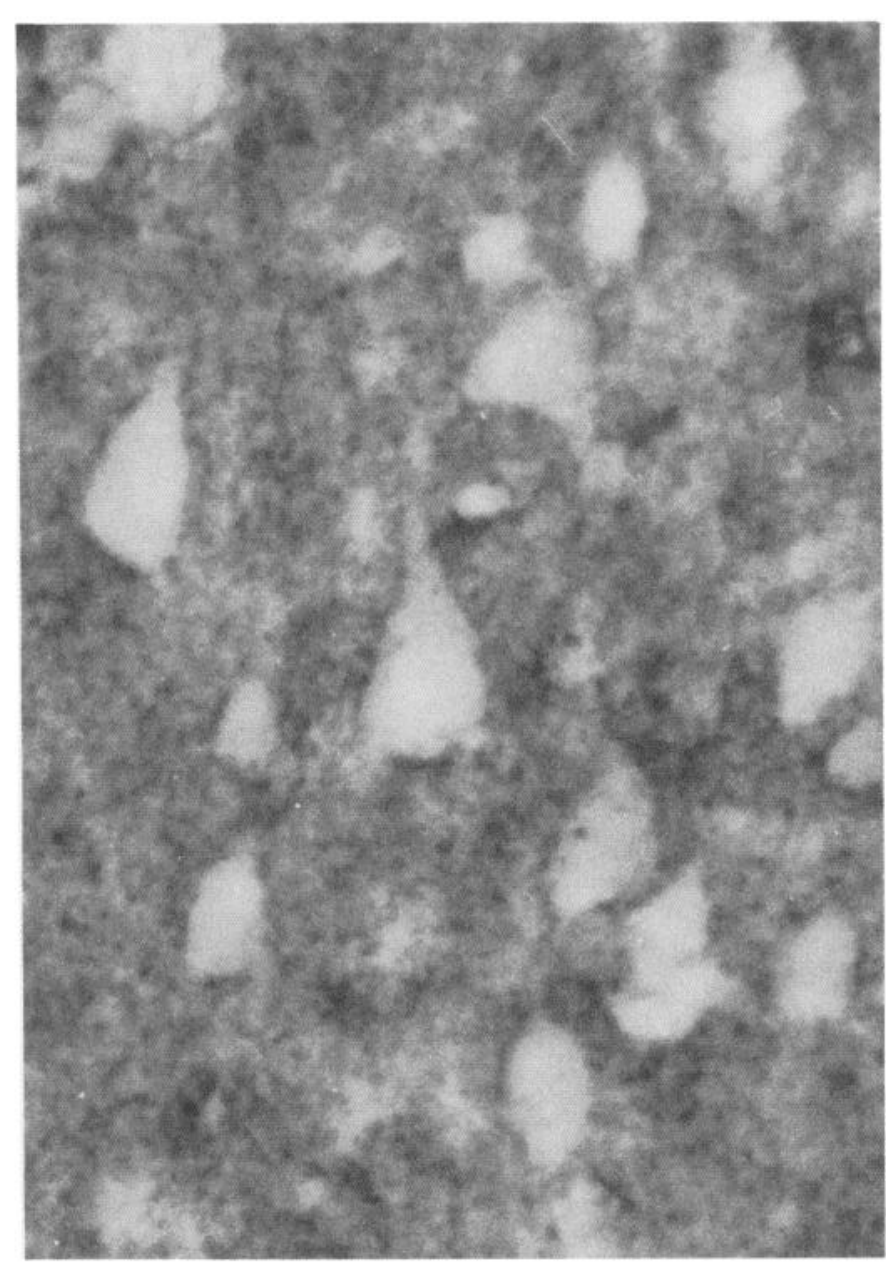

Figure 3. GAP-43 immunoreactivity in the adult rat cortex. The section $(35 \mu \mathrm{m})$ was reacted using as a primary antibody the rabbit affinitypurified anti-GAP-43 IgG (1/500 dilution), and photographed through a blue filter at $250 \times$ magnification. Neuropil in sensorimotor cortex (forelimb area) shows a granular staining, while neuronal somata, including those of the layer $\mathrm{V}$ pyramidal cells, are unstained.

striohypothalamic area and fundus striati (FStr, Fig. $5 B$ ), the ventral part of the lateral septum (LS, Figs. $4 B, 5 A$ ), and portions of the amygdala, most prominently the central (Ce, Fig. $5 C$ ), basolateral (BL, Fig. 5C), and lateral (La, Fig. $5 C$ ) nuclear complexes. The claustrum $(\mathrm{Cl}$, Fig. $5, A, B)$ showed moderately heavy staining, as did outer portions of the olfactory tubercle (Tu, Figs. 4, $B, C ; 5 A$ ).

In the neocortex, dense immunoreactivity was seen in layer I in all cytoarchitectonic regions (Figs. 4, $A-E ; 5 A-D$ ), and ended sharply at the boundary with the neuron-rich layer II (Fig. 6A). Other laminar differences were also apparent in the cortex, some of which changed at well-defined cytoarchitectonic boundaries. In some regions (e.g., occipital regions OclB, Oc1M, Oc2L, Oc2ML; Fig. $4 D$ ), a band of moderately dark staining occurred at a level corresponding to the uppermost part of layer $\mathrm{V}$, and another, wider band of relatively dark staining in layer VI. In parietal area 1 ( $\operatorname{Par} 1)$, the projection area of the vibrassae (Zilles and Wree, 1985), alternating zones of lighter and darker immunostaining occurred at midcortical levels, presumably coinciding with the barrel fields (Fig. 5, $B, C$ ). In the insular cortex (AI, GI), dark staining was seen at all levels, continuous with the dense staining in the claustrum $(\mathrm{Cl}$, Fig. $5, A, B)$.
Throughout the piriform cortex (Pir), extremely dense staining was found in the deeper portion of the plexiform layer $(1 \mathrm{~b}$, Fig. 6B). A lesser, though moderately dark staining was also seen in the more superficial dendritic field (layer la) and in layer 3 . Layer 2, containing the densely packed somata, showed almost no staining, consistent with the general scheme found throughout the brain.

Dense staining was also seen in transitional cortical areas that are best visualized in parasagittal sections near the midline (e.g., taenia tecta, TT; Figs. $4 A, 5 A$ ). In the hippocampus, the densest staining occurred in the outermost portion of the apical dendrites in CA1, in the stratum lacunosum moleculare (Slm); a somewhat lesser degree of staining was seen along the remainder of the apical dendrites of CA1 neurons (stratum radiatum, Rad) and on the basal dendrites of these same neurons (stratum oriens, Or) [Figs. 4, $A-E$, and 5, $C, D$ (not marked); 9]. Moderately dense staining was sharply delineated along the innermost dendritic segments of the dentate granule cells (stratum moleculare, Mol; Fig. $6 D$ ). Figure $6 C$ shows the paucity of staining in the pyramidal cell layer and within the apical dendrites themselves in the stratum radiatum of the CA1 field against a darkly stained background in the neuropil. Figure $6 D$, taken at higher magnification, shows that the immunoreactivity in the transitional area between the stratum moleculare and the granule cell layer of the dentate gyrus has a punctate appearance, consistent with the reported localization of the protein in presynaptic terminals (Gispen et al., 1985). It should be noted, however, that in no part of the hippocampal complex was the immunoreactivity as intense as in certain subcortical areas [e.g., BST (Fig. $4 B$ ) or $\mathrm{CPu}$ (Fig. 4, $C, D$ )].

In the anterior olfactory nucleus, dense staining was seen in all subdivisions, but particularly in the external segment (AOE, Fig. 7, top). Within the bulb itself, the internal and external plexiform layers (IPl, EPl, Fig. 7, top) were very light, while a modest degree of staining appeared in the glomerular (Gl, Fig. $5 B$ ) and inner granular layers (IGr, Fig. 7, top).

Although anti-GAP immunoreactivity was restricted primarily to the neuropil, certain axon bundles also showed considerable levels of staining. Most fiber pathways, including the optic tract (opt), showed no immunoreactivity whatsoever (Fig. 8 , top), consistent with the well-established developmentally regulated decline in the synthesis of GAP-43 in the retinal ganglion cells (Skene and Willard, 1981b; Freeman et al., 1986; Meiri et al., 1986; Moya et al., 1987). A similar absence of GAP immunostaining was found, for example, in the fasciculus retroflexus (fr, Fig. $4 B$ ), the mammillothalamic tract (mt, Fig. 5C), the internal capsule (ic, Figs. 4, $C, D ; 5, B, C$ ) and the pyramidal tract (py, Fig. $4 B$ ). However, some pathways showed distinctive staining, as in the centrally located axons of the corpus callosum (cc) shown in Figure 8, bottom. Even denser immunoreactivity was seen in the stria terminalis (st, Fig. $5 B$ ), consistent with the intense neuropil staining seen in the terminal distribution of these axons (e.g., in the BST).

A comparison of Figure $4, B$ and $E$, shows the similarity of results obtained using the 2 different anti-GAP antibodies. Control sections stained with 2 of the neutral sheep sera showed light staining in all neuronal somata (Fig. 4E), which differed entirely from the pattern seen with the anti-GAP immune serum (i.e., a complete absence of cell-body staining, but well-defined neuropil staining that varied widely in intensity in different regions); a third neutral sheep serum showed no staining whatever. Omission of the primary antibody gave completely blank 

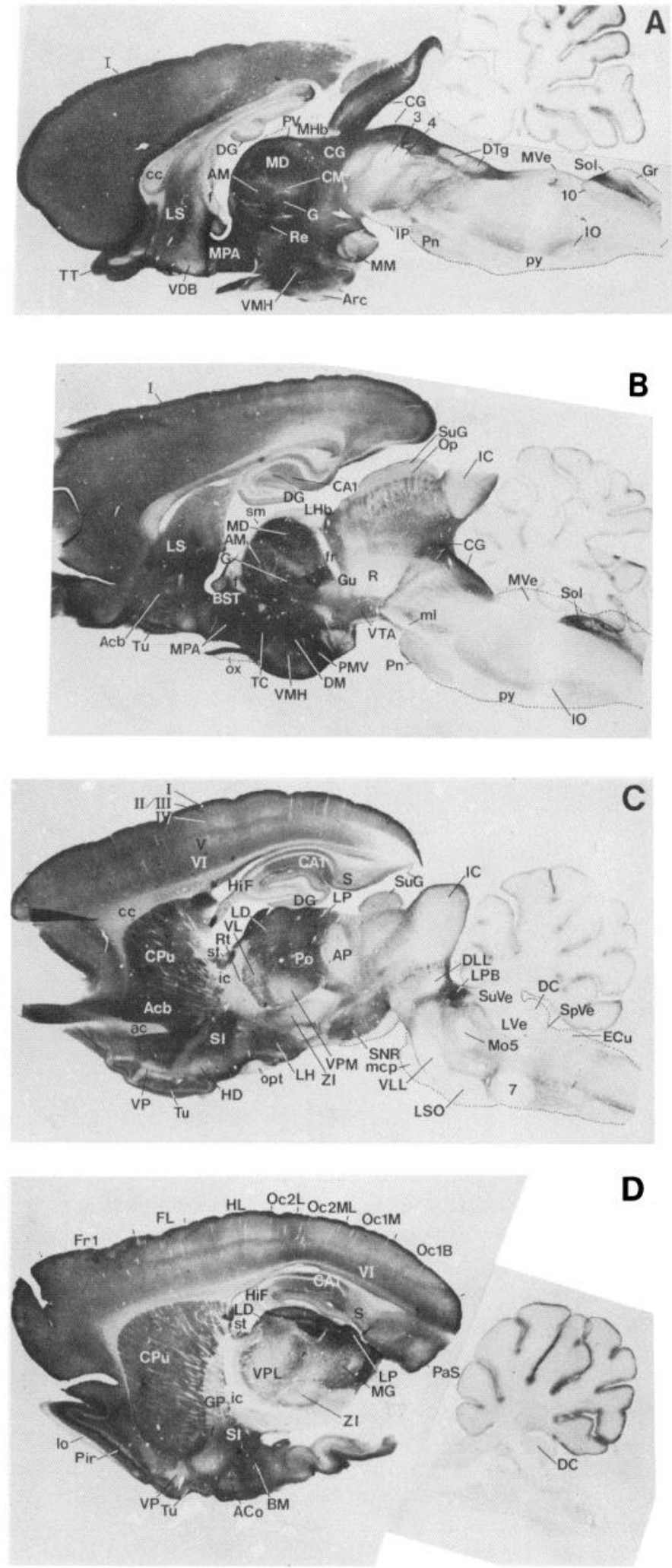

sections using a staining protocol that was otherwise identical to that used to generate the results seen in Figure $4, A-D$. As another control, preabsorbing specific anti-GAP IgGs using a 100-1000-fold excess of purified GAP-43 protein greatly reduced immunostaining (Fig. 9). Finally, when immunohistochemistry was carried out using affinity-purified anti-GAP IgGs
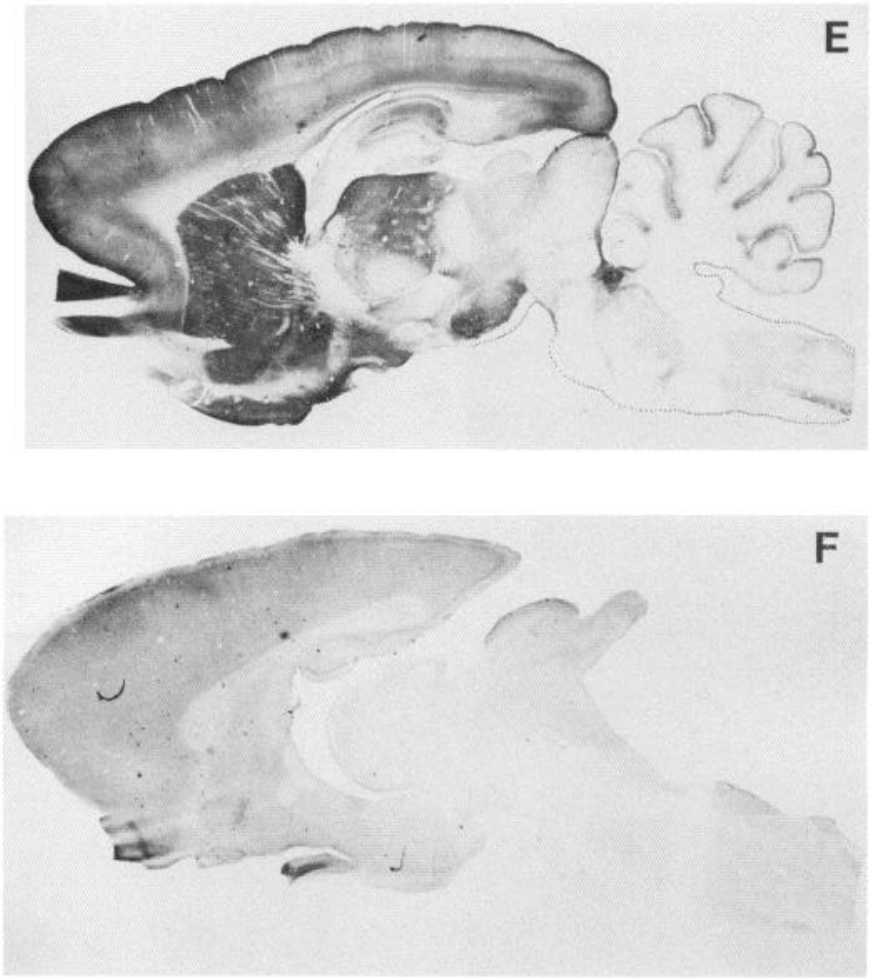

Figure 4. Parasagittal sections through the adult rat brain stained with $(A-D)$ affinity-purified rabbit anti-GAP/B-50 IgG at a $1 / 500$ dilution, $(E)$ sheep anti-GAP/B-50 (IgG fraction) at a $1 / 1000$ dilution, and $(F)$ nonimmune sheep serum at an equivalent concentration. Note the similarity in staining patterns obtained with the 2 different antibodies (cf. $C$ and $E)$. Abbreviations are listed in the Appendix.

from whole sheep serum, although the staining was very light, its distribution was similar to that described here using either the whole sheep serum, the total immune IgG fraction, or the affinity-purified antibody prepared in rabbits.

\section{Discussion}

The immunostaining found in this study was confined primarily to neuropil and showed a marked regional heterogeneity, with an overall increasing caudorostral gradient from the medulla oblongata up to the forebrain. Particularly dense staining was found in subcortical areas of the forebrain, in certain nuclei of the dorsal thalamus, and in specific laminae and cytoarchitectonic areas of the cortex. The 2 antibodies used in this study reacted specifically with the GAP-43/B-50 protein on Western blots, and gave an identical pattern of immunostaining, which was not seen in any of a number of control conditions. Consequently, the immunostaining described here is likely to be an accurate reflection of the distribution of the GAP-43/B-50 protein itself in the adult rat brain.

Several previous studies have used antibodies to demonstrate the subcellular localization of the B-50 protein (Oestreicher et al., 1981; Gispen et al., 1985), to examine its distribution in selected brain areas [i.e., hippocampus, cerebellum, and optic nerve (Meiri et al., 1986 (GAP-43); Oestreicher and Gispen 1986)], and for radioimmune assays (Oestreicher et al., 1986). In addition, endogenous phosphorylation studies using in vitro assays have described overall regional variations in the distribution of radiolabeled B-50, although these are difficult to interpret because of possible variations in the prior phosphoryl- 

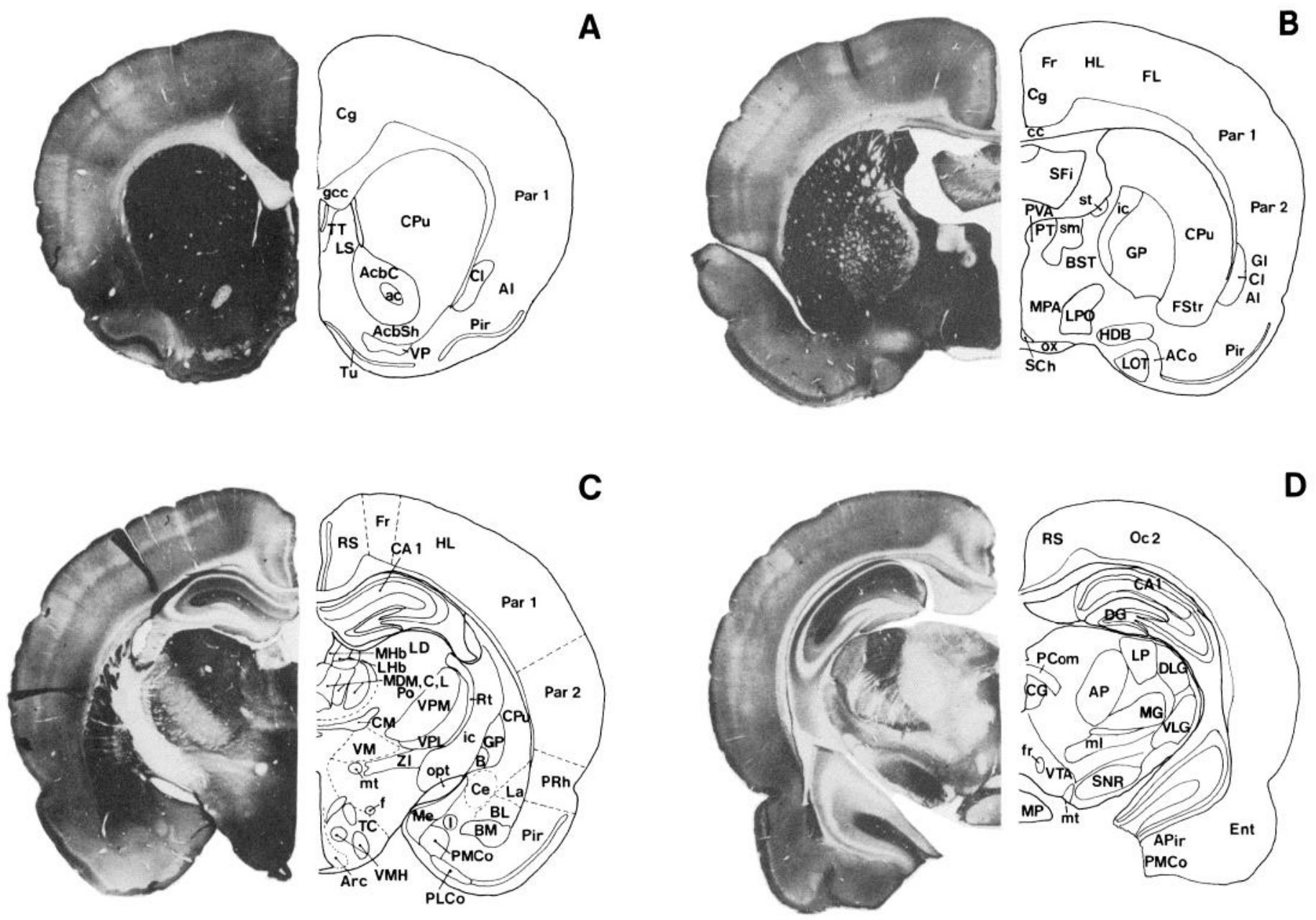

Figure 5. Coronal sections through the rat brain reacted with the sheep anti-GAP/B-50 antiserum (1/2000, 3 Da; tissue fixed in $4 \%$ paraformaldehyde $/ 0.2 \%$ glutaraldehyde, postfixed for $2 \mathrm{hr}$, cryoprotected in $30 \%$ sucrose, and cut at $35 \mu \mathrm{m})$. Abbreviations are listed in the Appendix.

ation state of the protein and in the activity and distribution of its kinase (Kristjansson et al., 1982). Our results essentially confirm those of earlier studies in showing, e.g., an identical pattern of immunostaining in the hippocampal formation and dentate gyrus (cf. Oestreicher and Gispen, 1986), undetectably low levels in the adult optic nerve (cf. Meiri et al., 1986), and high overall levels of the protein in some of the same general areas previously noted. However, by using immunocytochemistry to examine the detailed anatomical distribution of the protein throughout the brain, the present results allow us to identify the precise neural structures in which the protein is relatively enriched or absent, to relate these findings to known anatomical and functional data, and thereby to begin to refine our concepts concerning the relationship of GAP-43/B-50 to neural functioning.

Some of the most intense immunostaining in the brain was in a continuum of subcortical and diencephalic structures that have been implicated in the integration and control of complex emotions and behaviors. This continuum includes the caudateputamen $(\mathrm{CPu})$, olfactory tubercle $(\mathrm{Tu})$, nucleus accumbens (Acb), ventrolateral septum, bed nucleus of the stria terminalis (BST), substantia innominata (SI), and portions of the amygdala (especially basolateral and central nuclear complexes), the preoptic area, and the medial hypothalamus. In general, it might be noted (Table 1) that the first 3 of these ( $\mathrm{CPu}, \mathrm{Tu}$, and Acb) receive innervation from the entire cortical mantle and are major targets of ascending dopaminergic pathways (anteroventral thalamic nucleus, substantia nigra pars compacta); much of this region also receives projections from the basolateral complex of the amygdala (De Olmos et al., 1985; Heimer et al., 1985). More caudal portions of this continuum receive some of the same afferents (with the most prominent cortical afferentation being allocortical limbic or infralimbic areas; Table 1), and are also interconnected with one another.

In the cortex, intense staining was seen in layer I throughout the neocortex and juxtallocortex, and in the intermediate plexiform layer (layer Ib) of the piriform cortex. Layer I of cortex contains few neuronal cell bodies, but is rich in synaptic connections onto the apical dendrites of pyramidal cells that lie in deeper layers (primarily II, III, and V). This densely staining plexus most likely represents the nerve terminals of intracortical associations arising from layer II and III neurons in other cortical areas. Layer I also contains the terminals of axons arising in the ventromedial nucleus of the thalamus, and is the preferential projection area of noradrenergic projections from the locus coeruleus (Faull and Mehler, 1985; Loughlin and Fallon, 1985). In addition to the dense layer I staining, a thin band of moderate staining was seen in much of the neocortex at the top of layer V, and a wide band in layer VI. This pattern varied 

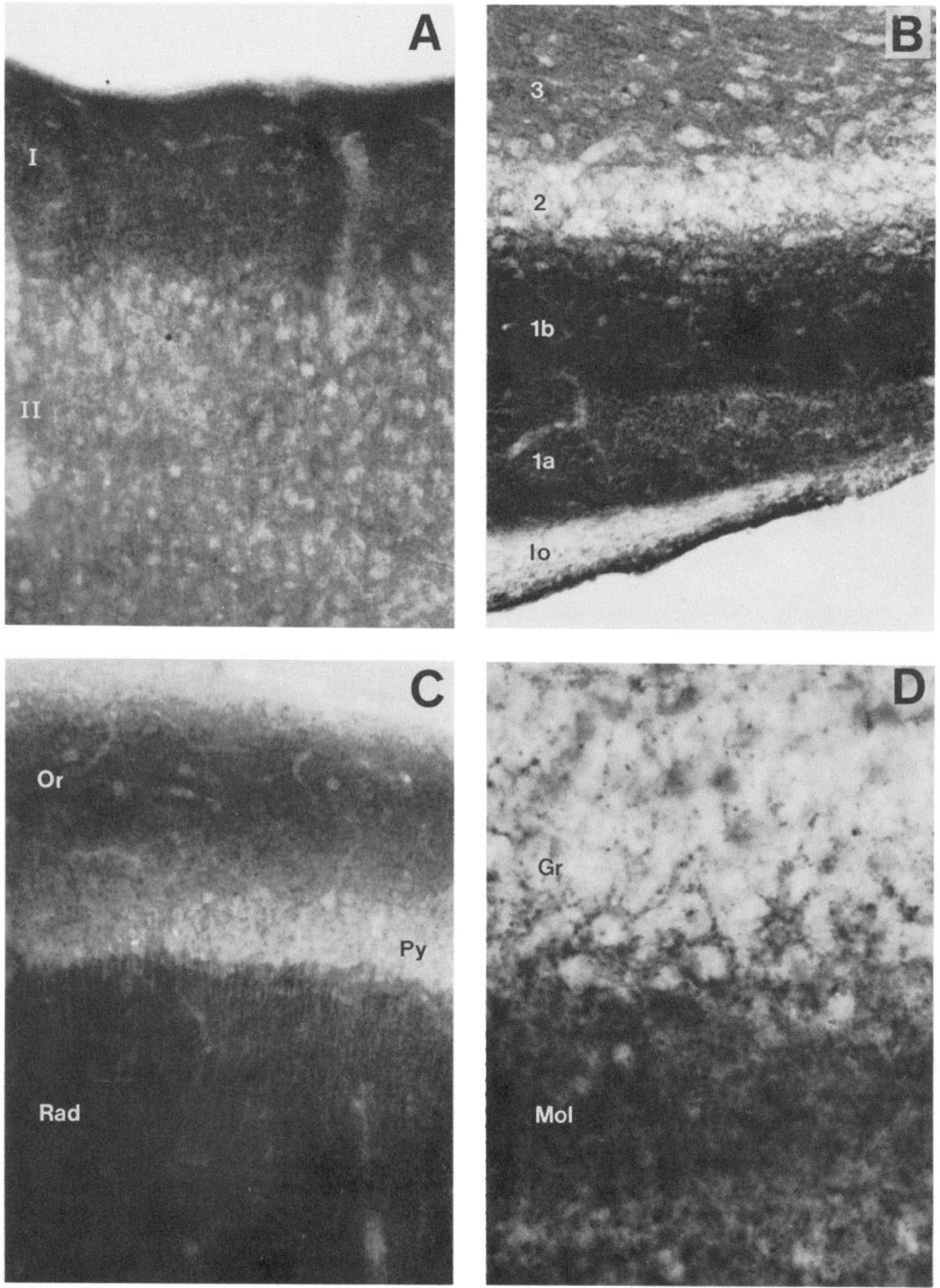

Figure 6. GAP/B-50 immunostaining in the cortex and hippocampus (sheep anti-GAP/B-50 IgG fraction, 1/1000). A, Throughout most of the neocortex, intense staining in the neuropil of layer $I$ ends sharply at the boundary with layer $I I$. $B$, In the piriform cortex, the more proximal segments of apical dendrites (layer $l b$ ) arising from neurons in layer 2 show intense staining. Note absence of somatic staining in layer 2 . $C$, The CAl field of the hippocampus shows dark staining in the stratum oriens $(\mathrm{Or})$, in the stratum radiatum (Rad), and even denser staining in the stratum lacunosum moleculare (not shown). Note the absence of staining in the pyramidal cell $(P y)$ layer itself and within the apical dendrites. $D$, In the dentate gyrus, the innermost segment of dendrites arising from the granule cells $(\mathrm{Gr})$ shows a punctate pattern of GAP-43 immunostaining, consistent with the reported localization of the protein in presynaptic terminals (Gispen et al., 1985). 

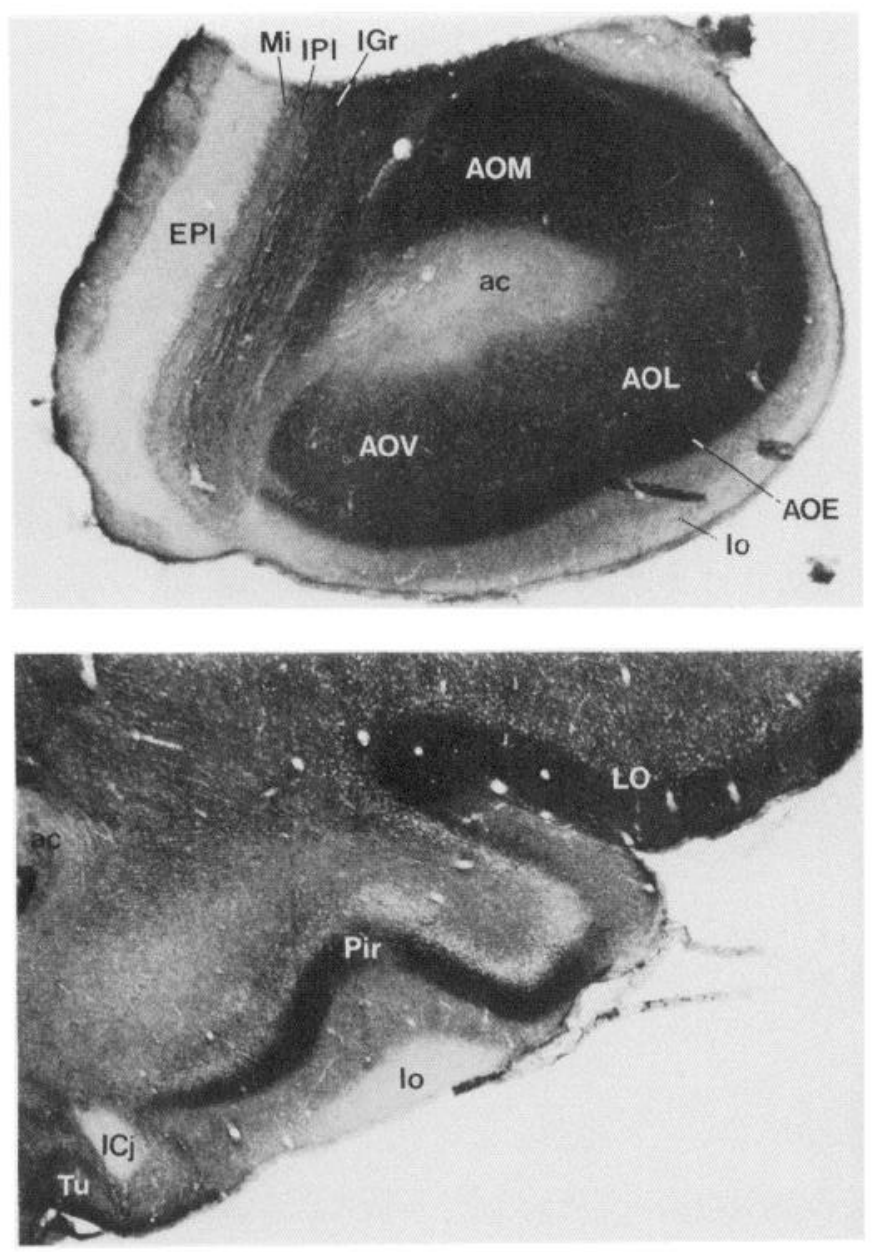

Figure 7. GAP/B-50 immunostaining in the caudal olfactory bulb and anterior olfactory nucleus (AON; top), and in the ventral anterior telencephalon (bottom). Sections were stained using sheep anti-GAP/ B-50 serum at a 1/2000 dilution (3 Da) as the primary antibody. Intense staining is seen in all nuclei of the AON, particularly the external segment $(A O E$, top), in the inner segment of the plexiform layer of the piriform cortex (Pir, bottom), the olfactory tubercle (Tu, bottom), and in layer I of the lateral orbital cortex ( $L O$, bottom). Other abbreviations are given in the Appendix.

somewhat across cytoarchitectonic zones, and may provide a potentially interesting perspective on hodological and functional differences among various cortical areas. For example, in the parietal cortex (Par 1), discontinuities in the infragranular staining (Fig. 5, $A, B$ ) appear to coincide with the barrel fields (Zilles and Wree, 1985), while in visual areas the layer VI staining appears to be rather pronounced. The insula, which is one of the only cortical areas that is densely stained throughout (Fig. $5 \mathrm{~A}$ ), receives a unique convergence of olfactory, visceral, nociceptive, and limbic inputs (Table 1). It should be noted that all stages of the ascending viscerosensory pathway, including the principal relay, the nucleus of the solitary tract (Sol), the medial parabrachial nucleus, the gustatory nucleus of the thalamus, and the insula, stand out in showing intense GAP-43/B50 immunoreactivity.

The pattern of GAP-43/B-50 staining in the hippocampal formation $(\mathrm{HiF})$ has been described previously (Oestreicher and Gispen, 1986), and the present results are in complete agreement in showing the densest staining to be in the CA1 field of Am-
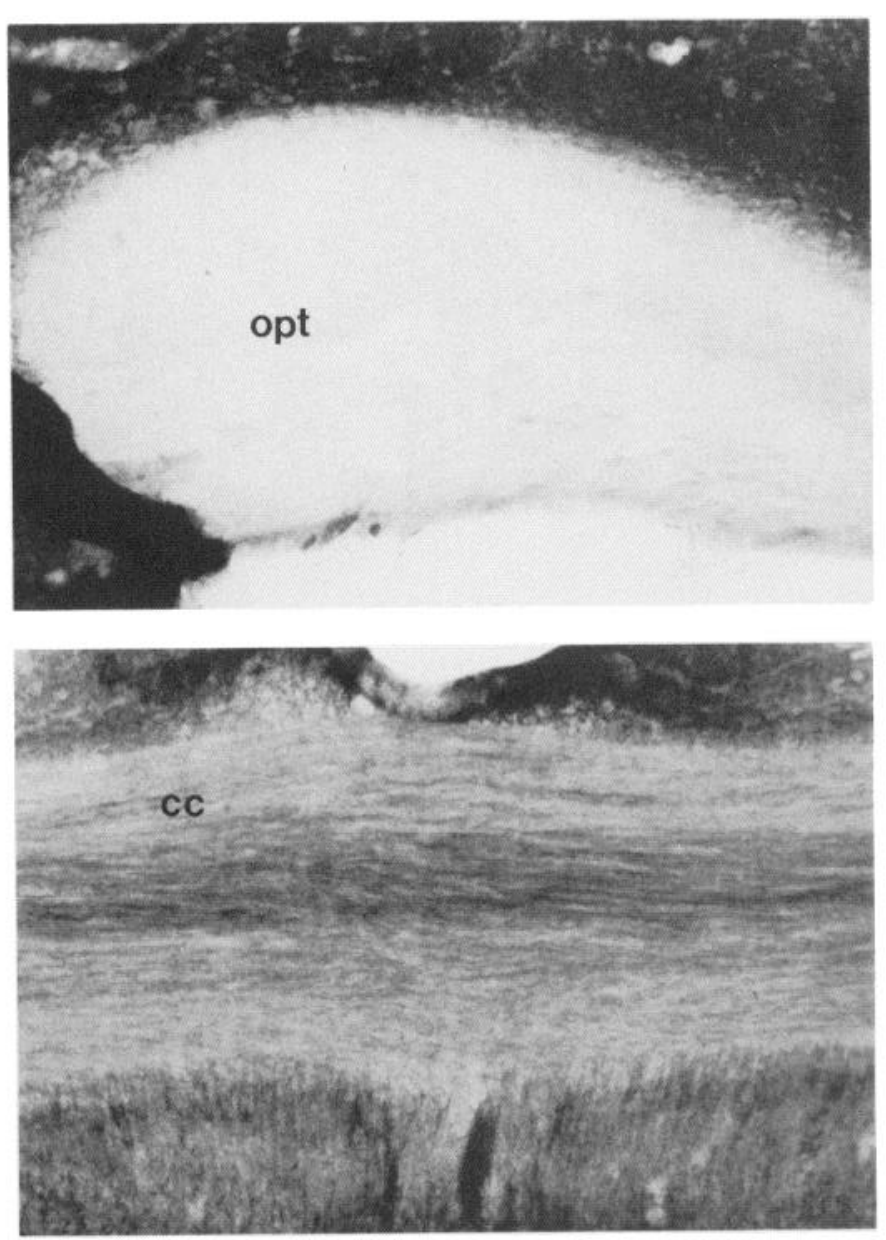

Figure 8. GAP-43 immunostaining in axons (sheep anti-GAP/B-50 antibody, 1/2000 dilution). The optic tract (opt, top), shown here at the level of the hypothalamus, shows essentially no staining, consistent with the very low levels of synthesis and axonal transport of GAP-43 that have been described in the optic pathway of adult mammals (Skene and Willard, 1981b; Freeman et al., 1986; Meiri et al., 1986; Moya et al., 1987). Some fibers of the corpus callosum ( $c c$, bottom) are darkly stained, however, and presumably transport GAP-43 from smaller pyramidal neurons in one hemisphere to the other side. Below the cc, fibers of the dorsal fornix (unlabeled) are also stained.

mon's horn and in the innermost segment of the stratum moleculare (Mol) of the dentate gyrus (DG). This distributional pattern would suggest that a likely source of the GAP/B-50-rich terminals is the CA3 pyramidal neurons, whose projections (Bayer, 1985) closely match the staining pattern found here. However, other projections to the hippocampal formation that also correspond with the present pattern of immunostaining, and that must hence be considered as other possible sources of the GAP staining, include the piriform cortex (to CA1), medial septum (to CA 1 and $\mathrm{Mol}$ ), and nucleus reuniens. It is of interest to note that studies on synaptic plasticity have emphasized the phosphorylation of the cognate protein F1 in the dentate gyrus following tetanic stimulation of the perforant pathway (Lovinger et al., 1985; Nelson and Routtenberg, 1985). Yet, in contrast to the dense immunostaining seen in the CAl field and in the innermost part of the dentate molecular layers, the amount of F1 (GAP/B-50) present in areas receiving most of the perforant pathway (entorhinal) input is considerably more modest (i.e., in the outer segments of Mol and the CA3 field) (Figs. 4, C, D; 
$5 D)$. Thus, if the phosphorylation of this protein is in fact an essential component of synaptic plasticity, these results would imply that other areas of the hippocampal formation might actually exhibit more plasticity than the perforant pathwaydentate projection.

In contrast to the dense immunostaining found in certain integrative and limbic areas of the forebrain, sensory-specific relay areas, motor areas controlling the skeletal musculature, and most of the reticular formation showed conspicuously low levels of staining. GAP immunostaining was essentially absent, for example, at the first several relay stations of ascending auditory information (DC, MSO, LSO, DLL, VLL, and Tz), very low in the inferior colliculus, and modest in the medial geniculate nucleus. Staining was also absent in the dorsal column nuclei (Cu, Gr) and vestibular complex, very low in cerebellum, and light in the ventrobasal complex of the thalamus (VPL and VPM) and in most areas receiving visual inputs (e.g., SuG of the superior colliculus and the dorsal lateral geniculate nucleus). With regard to motor and premotor areas, staining was essentially absent in nucleus ruber (R, Fig. $4 B$ ) and the motor nuclei of the oculomotor, trochlear, trigeminal, and facial nerves ( 3 , $4,5,7$, Fig. 4, $A, C$ ). Thus, in comparison with those integrative and limbic areas of the forebrain that show high levels of GAP43/B-50, primary somatosensory, somatomotor, and reticular formation areas of the brain stem may conceivably be more "hard-wired" in the adult brain and less capable of undergoing long-term changes in synaptic function (or morphology).

Insofar as the phosphorylation of GAP-43/B-50 is regulated by protein kinase C (PKC: Zwiers et al., 1980; Aloyo et al., 1982; De Graan et al., 1985; Nishizuka, 1986), it is of interest to compare the anatomical distribution of the 2 proteins. Using ${ }^{3} \mathrm{H}$-phorbol ester, which is presumed to bind specifically to $\mathrm{PKC}$, one recent study (Worley et al., 1986) has shown the kinase to be most abundant in many of the same areas that show dense GAP-43/B-50 immunostaining (e.g., layer I of cortex; Or and Rad of CA1; substantia nigra; nucleus accumbens, caudate-putamen) and low or absent in some of the areas that showed little staining here (e.g., nucleus ruber, nucleus gracilis). Instances where PKC levels are disproportionately high relative to those of GAP-43/B-50 (e.g., the cochlear nuclei or the molecular layer of the cerebellum) might be readily explained by the fact that GAP-43/B-50 is only one of several PKC substrates, and that the enzyme may be required in these areas for regulating the phosphorylation of other proteins. More surprising, however, are those regions that have high levels of GAP-43/B-50 but low levels of PKC (e.g., in several areas of the medial hypothalamus, including $\mathrm{Pe}, \mathrm{VMH}$, and $\mathrm{Pa}$ ). Such disparities raise the possibility that GAP-43/B-50 may function somewhat independently of $\mathrm{PKC}$ regulation in some parts of the brain.

Since levels of GAP-43/B-50 in neuronal somata are undetectably low, immunohistochemistry alone cannot be used to identify the exact neural populations that give rise to the nerve terminals visualized in this study. This problem can be addressed, however, through the use of cDNA probes to localize the GAP-43/B-50 mRNA in specific neurons by in situ hybridization, or regionally by using RNA (Northern) blots. Preliminary studies by Northern blot analysis, using a cDNA to the rat GAP-43 gene, indicate that levels of the mRNA are high in rat certebral cortex, striatum, and midbrain, modest in hippocampus and brain stem, and very low in cerebellum (Neve et al., 1987). Thus, it is clear that the presence of the protein in certain
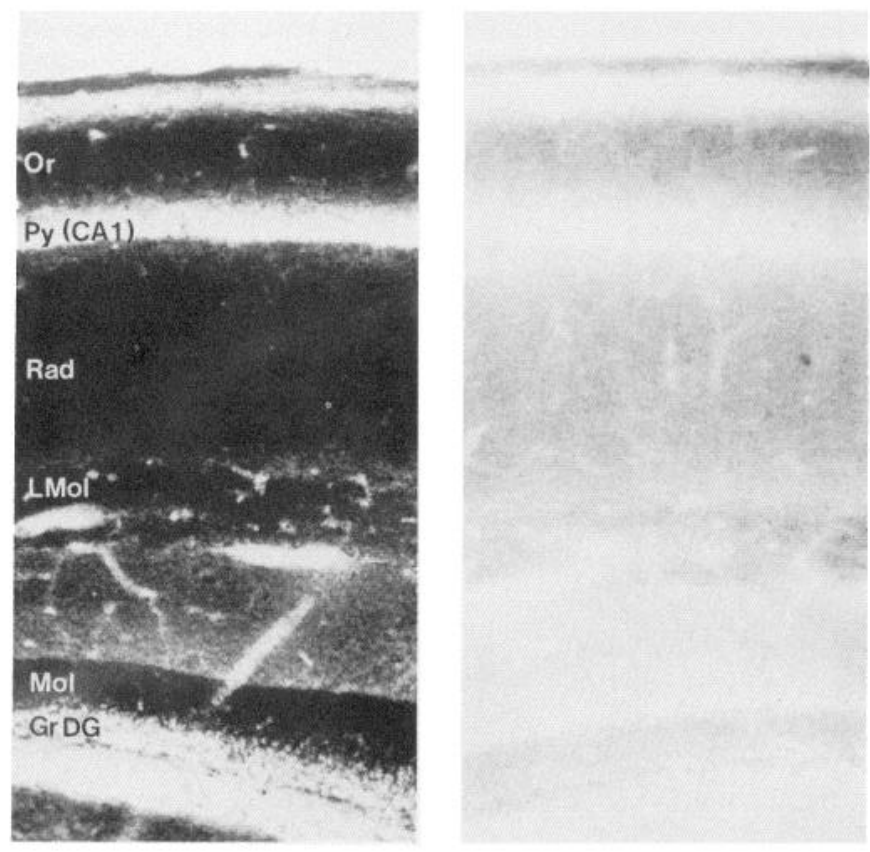

Figure 9. Preabsorption control. Left, GAP-43 immunostaining in the hippocampal formation, using as a primary antibody the sheep antiGAP serum at a 1/2000 dilution. Laminar distribution is identical to that reported by Oestreicher and Gispen (1986). Right, When the primary antiserum was reacted overnight with a 100-1000-fold excess of pure GAP-43 protein and centrifuged prior to use, immunostaining decreased markedly in all parts of the hippocampus. Abbreviations listed in the Appendix.

areas of the adult brain reflects an ongoing expression of the GAP-43/B-50 gene in particular neurons. Moreover, this would suggest, for example, that the high levels of GAP-43/B-50 seen in the caudate-putamen (and perhaps in the substantia nigra pars reticulata) may arise from neurons intrinsic to the caudateputamen, while the intense layer I staining in cortex is likely to arise from intracortical associations.

The results of the present study raise a number of issues concerning the significance of GAP-43/B-50 in the adult brain. GAP-43 was originally conceptualized as an essential component of axon outgrowth or synaptogenesis, since studies in a number of neural systems had shown it to be synthesized and transported to nerve endings selectively during development and regeneration(Benowitzetal., 1981; SkeneandWillard, 1981a, b; Benowitz and Lewis, 1983; Skene, 1984; Kalil and Skene, 1986). As the results indicate, the particular pathways that had been examined in those studies are indeed ones in which levels of the protein do become very low in the adult brain (e.g., targets of the optic nerve and pyramidal tract: the superficial gray of the superior colliculus and dorsal lateral geniculate nucleus; and the cranial nerve nuclei and nucleus ruber). However, although this developmentally regulated decrease is representative of the changes seen in the brain as a whole (Jacobson et al., 1986), the GAP-43 gene does continue to be expressed at considerable levels in certain neurons throughout life (Neve et al., 1987), and high levels of protein clearly remain in presynaptic terminals of specific brain regions. Since, in at least one area of the brain, the phosphorylation of this protein $(F 1)$ has been linked with the events that underlie long-term potentiation (Lovinger et al., 1985; Nelson and Routtenberg, 1985), more recent formulations 
Table 1. Areas of densest anti-GAP-43 immunostaining and some of their major afferents

Region

Ant. olfactory n. (AON)

Cortex, hippocampus

Taenia tecta (TT)

Piriform (Pir., esp. layer $1 \mathrm{~b}$ )

Insula (AI, GI)

Hippocampal formation (HiF) CA1 field

Dentate (inner molecular layer)

Layer I (throughout)

Subcortical telencephalon

Olfactory tubercle ( $\mathrm{Tu}$ )

Caudate-putamen (CP)

N. accumbens (Acb)

Fundus striati (FSt)

Lat. septum (LSV, SHy)

Bed $\mathbf{n}$. stria terminalis (BST)

Substantia innominata (SI)

Amygdala: cent. group (Ce)

Basolateral group (BL)

Dor. thalamus

Paraventricular (PVA, PVP)

Mediodorsal (MD, esp. MDM)

Reuniens (Re)

Gelatinosus (G)

Laterodorsal (LD)

Gustatory (Gu; VPPC)

Lateroposterior (LP)

Posterior (Po)

SPFPC

Hypothalamus/preoptic a.

Med. preoptic (MPA)

Paraventricular (PaAP, $\mathrm{PaV})$

Periventricular $(\mathrm{Pe})$

Arcuate (Arc)

Ventromedial (VMH, shell)

Dorsomedial (DM)

Tuber cinereum (TC)

Premammillary (PMD, PMV)

Supramammillary (SuM)

Midbrain, isthmus, pons, medulla

Substantia nigra pars reticulata (SNR)

Cent. gray
Major afferents

Refs.

Olfactory bulb (OB); cortex (Cx: Pir, Ent, S); subcortical (HDB, VDB, BST); hypothalamus $\quad \mathrm{a}, \mathrm{b}$ (Hypothal: TC)

OB, AON, Cx (Pir, Ent, S)

a, $b$

$\mathrm{OB}, \mathrm{AON}, \mathrm{Cx}(\underline{\mathrm{Pir}}, \mathrm{TT}$, Ent, insula); amygdala (Amyg: olfactory areas; $\underline{\mathrm{BL}}, \underline{\mathrm{Ce}}$ ); subcortical (SI, VDB, HDB); Hypothal (LH, LPO); thalamus (Thal: midline nuclei); VTA, LC, raphe

OB; Cx (Pir, Ent); Amyg (BL, cortical group); Thal (MD, PT, PVA, VM, $\underline{\text { G }} \underline{\mathrm{Gu}}, \mathrm{CM})$; brain stem $(\underline{M P B})$

Cx (S, Pir, Ent); HiF (Ca3); subcortical VDB, MS), Thal (Re); brain stem (raphe, LC) b, e

HiF (CA3), MS, LC, raphe

Intracortical associations; Thal (VM); raphe, $\underline{\mathrm{LC}}$

OB, AON, Cx (prefrontal, Pir, S, Ent); Amyg (BM, BL); AVT; raphe

All of neocortex, allocortex; $\mathrm{CP}$; Amyg (BL, Ce); En; Thal (intralaminar and vent. complexes; LP, Po, PT, PVA, PVP); SNC, STh, raphe

$\mathrm{Cx}$ (Pir, Ent, PRh, prefrontal, AI); Amyg (BL); VP; AVT

Amyg (olfactory grup; $\mathrm{BM}, \mathrm{Ce}$ ); $\mathrm{Si}$; VDB

HiF, S; Hypothal (AHA, MPO, VMH); raphe

AOB, AON; cortex (S, Ent, AI, PRh, infralimbic); Acb, FSt, BST, SI; Amyg (Ce, Me, BL, BM, AHi); Hypothal (MPA, AHA, VMH, Arc); SNC, AVT, LPB, MPB, LC; raphe; $\mathrm{A}_{1}$, $\mathrm{A}_{2}$

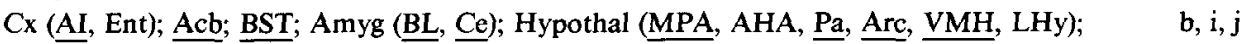
Thal (PVA, PVP, PT, IAM); $\overline{C G}, \underline{\text { LPB }}$, MPB, raphe, Sol, $A_{1}, A_{2}$

Cx (infralimbic, AI, GI, Ent, PRh, Pir, S); HDB, FSt, SI, BST; Amyg (olfactory; BL); Hypothal (LPO, LHy, VMH, Arc, PVM, PMD; Thal (PVA, PVP, PT, Re, AM, MG, SPF, PF); VTA, SNC, CG, LC, MPB, LPB, raphe, Sol, $A_{1}, A_{2}$

Cx (Pir, TT, Ent, PRh, prelimbic, S, AI, GI); HDB, VP, GP, BST, SI; Hypothal (VMH, $\underline{\mathrm{DM}}, \underline{\mathrm{PMD}}$, PMV, SuM, LPO); Thal (Re, PT, PVA, PVP, IAM, $\overline{\mathrm{CM}}, \underline{\mathrm{MDM}}, \mathrm{SPF}, \mathrm{M} G)$ $\overline{\mathrm{AVT}}, \overline{\mathrm{SNC}}, \underline{\mathrm{MPB}}, \underline{\mathrm{LPB}}, \underline{\mathrm{LC}}, \underline{\mathrm{CG}}$, raphe, $\mathrm{A}_{8}$

Cx (AI, GI); CG, MPB, LPB, raphe

Cx (Pir, prefrontal); Acb, Tu, VP, GP, En; Amyg (Me, BL); SNR, raphe

$\mathrm{Cx}$ (infralimbic, $\mathrm{Cg}, \mathrm{S}$ ); Hypothal (VMH, MPA); CG, SNR, raphe

$\mathrm{Cx}$ (orbital prefrontal, insular); rexed lamina I (cord); $\mathrm{Sp5}$

Cx (S, RSG); SNR

Cx (insula); MPB

$\mathrm{Cx}(\mathrm{Ocl}, \mathrm{Oc} 2 \mathrm{~L}, \mathrm{Oc} 2 \mathrm{M}, \mathrm{Te}$; insula) Thal (ZI, Rt); AP, SC, $\underline{\mathrm{LC}}$, raphe

$\mathrm{CX}$ (SIII [5a]; ?polysensory input)

Amyg

Cx (Pir; frontal, S); Tu; MS, LS, SI, BST; Amyg (Me, AHi, BM, BL, Ce); Hypothal $\quad$ b, e, h

$(\underline{\mathrm{VMH}})$; raphe, Sol, $\mathrm{A}_{1}$

MS; BST; Amyg (Me, Ce); Hypothal (MPA, AHA, DM, LHy, Arc, SCh); LC, LPB, raphe, b, h-j, 1 Sol, $A_{1}$

MS, Amyg (BM), AHA, LC, raphe

$\mathrm{Cx}$ (S); AHi; MS, VDB

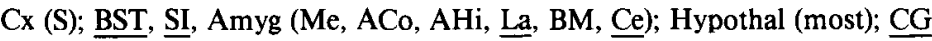

BST; Amyg ( $\underline{\text { Ce }) ; ~ H y p o t h a l ~(V M H, ~ m o s t ~ o t h e r s) ; ~ L C ~}$

$\mathrm{Cx}(\mathrm{S})$

Amyg (Me, BM); Hypothal (VMH, AHi); raphe

Cx (Pir); Tu, SI; Thal (Re); $\underline{\mathrm{CG}}$

Cx (prefrontal); CP, GP, Acb, VP; Amyg (Ce); LHb; PF; Hypothal (AHA; LPO); STh; SNR; LPB, MPB, raphe

Cx (insula, Cg, S); Acb, BST, Si, Amyg (Ce); LHb; Thal (Re, ZI, PF); Hypothal (LPO, VMH, LHy, PMD); SNR, VTA, DpG, CnF, RF, raphe 
Table 1. Continued

\begin{tabular}{|c|c|c|}
\hline Region & Major afferents & Refs. \\
\hline Parabrachial n. (LPB, MPB) & Cx (insula); Acb, SI, FSt, BST, Amyg (Ce); Hypothal ( $\underline{\mathrm{PVH}}, \underline{\mathrm{PaV}}) ; \underline{\mathrm{SNR}} ;$ raphe; Amb; Sol & $\mathrm{b}, 1(?)$ \\
\hline Locus coeruleus $\overline{(\mathrm{LC})}-$ & $\begin{array}{l}\text { BST, Amyg }(\underline{\mathrm{Ce}}) ; \text { Thal }(\mathrm{VL}, \mathrm{PF}) ; \text { Hypothal }(\underline{\mathrm{Arc}}, \mathrm{LPO}, \overline{\mathrm{VM}}, \overline{\mathrm{PL}}, \overline{\mathrm{DM}}, \underline{\mathrm{Pa}}) ; \mathrm{RF}, \underline{\mathrm{CG}}, \\
\text { AVT, SNR; Cb, vestibular nuclei; other monoaminergic neurons }\end{array}$ & j \\
\hline N. solitarius & 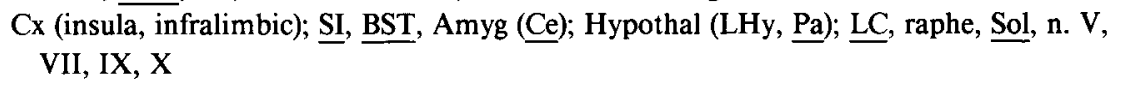 & \\
\hline
\end{tabular}

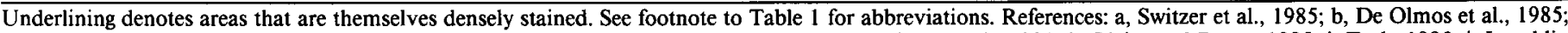

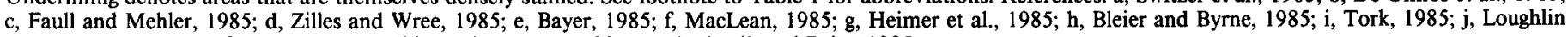
and Fallon, 1985; k, Sefton and Dreher, 1985; 1, Armstrong, 1985; m, Andrezik and Beitz, 1985.

have suggested that whereas GAP-43 may play a time-limited role in the establishment of perhaps all synaptic relationships, it may continue to play an analogous role in a select subset of synapses in relation to functional plasticity in the adult brain (Routtenberg, 1985; Pfenninger, 1986; Benowitz and Schmidt, 1987; Benowitz and Routtenberg, in press). The distributional pattern described in the present study raises the question of whether all areas that show high levels of GAP-43 in the adult brain are capable of undergoing some form of functional plasticity, or whether the presence of the protein in some of these areas might reflect some other events at the synapse (e.g., general signal transduction; Zwiers et al., 1987). The fact that the highest levels of the protein are found in integrative and limbic areas of the rat brain is particularly intriguing with regard to the former notion, although the relatively widespread distribution in subcortical areas was unanticipated and difficult to interpret. It is of interest to note, however, that in the human brain the gene encoding GAP-43 is expressed in a much more restricted fashion, with highest levels in the associative neocortex and only very low levels in primary sensory or motor cortical areas or subcortical structures (Neve et al., 1987).

\begin{tabular}{|c|c|}
\hline $\begin{array}{l}\text { Appendix. I } \\
\text { 1986) }\end{array}$ & List of abbreviations (based on Paxinos and Watson, \\
\hline 3 & Oculomotor $\mathrm{n}$. \\
\hline 4 & Trochlear $\mathrm{n}$. \\
\hline 6 & Abducens $\mathrm{n}$. \\
\hline 7 & Facial $n$. \\
\hline 10 & Dorsal motor $n$. of vagus \\
\hline A $1-A 7$ & Noradrenaline cell groups A1-A7 \\
\hline A $8-A 10$ & Dopamine cell groups A8-A10 \\
\hline ac & Ant. commissure \\
\hline aci & Accumbens intrabulbar part \\
\hline Acb & N. accumbens \\
\hline AcbC & Acb core \\
\hline $\mathrm{ACo}$ & Ant. cortical amyg. $n$. \\
\hline $\mathrm{AD}$ & Anterodorsal thalamic $\mathrm{n}$. \\
\hline AHA & Ant. hypothalamic a., ant. part \\
\hline $\mathrm{AHi}$ & Amygdalohippocampal a. \\
\hline Al & Agranular insular cortex \\
\hline AM & Anteromedial thalamic $\mathrm{n}$. \\
\hline Amyg & Amygdala \\
\hline $\mathrm{AOB}$ & Accessory olfactory bulb \\
\hline AON & Ant. olfactory $n$. \\
\hline \multicolumn{2}{|l|}{ AOD, -E, -L, } \\
\hline$-M,-P,-V$ & AON dors., ext., lat., med., post., and vent. parts \\
\hline AP & Ant. pretectal $n$. \\
\hline Arc & Arcuate $\mathrm{n}$. \\
\hline AV & Anteroventral thalamic $\mathbf{n}$. \\
\hline
\end{tabular}

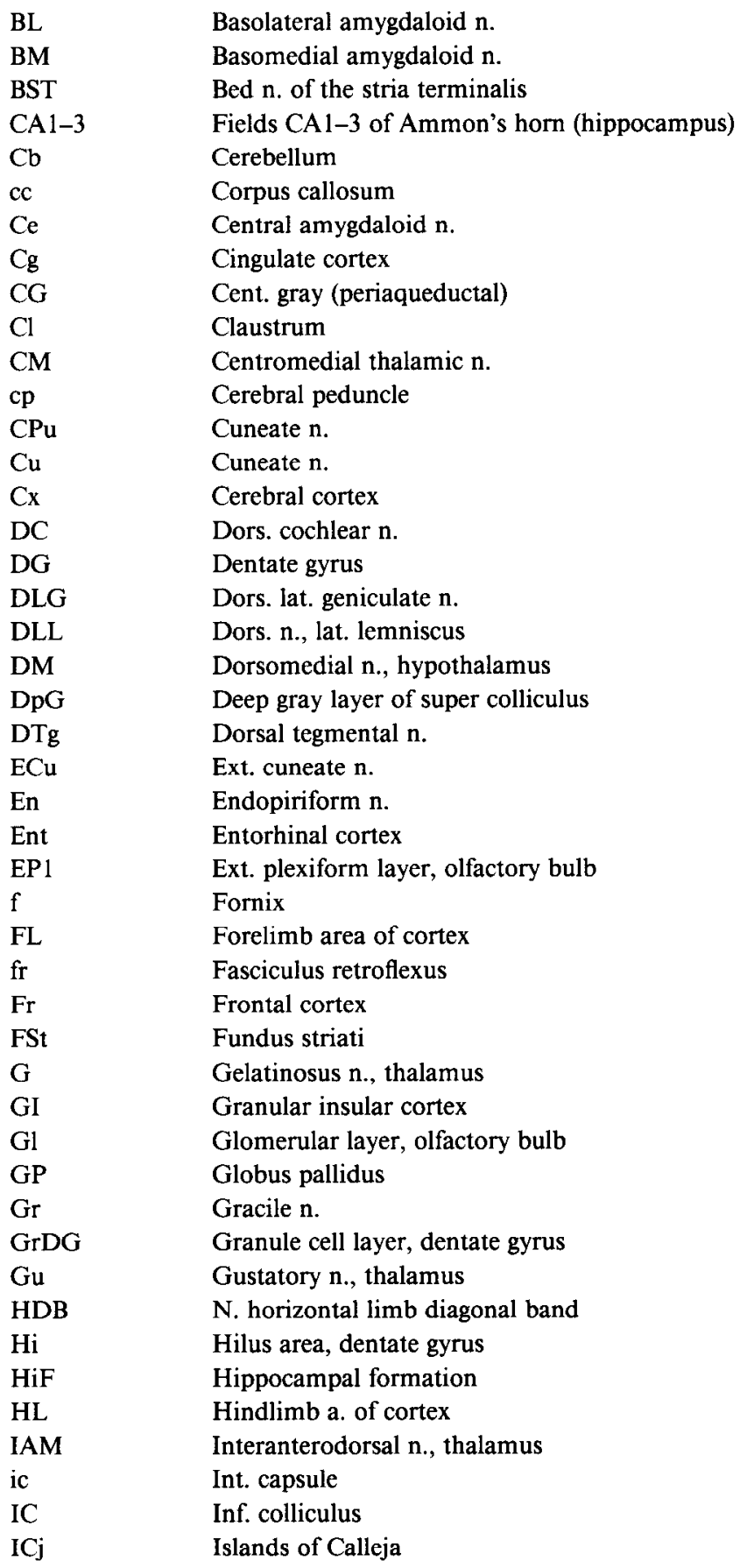

$\bar{a}$ a., Area; amyg., amygdala; ant., anterior, cent., central; dors., dorsal; ext., external; inf., inferior; int., internal; lat., lateral; med., medial; post., posterior; sup., superior; vent., ventral. 
IL

IMD

IO

IP

IPI

La

LC

LD

LH

LHb

LHy

LM

LMol

lo

LO

LP

LPB

LPO

LSO

LS

LVe

MD

MDC

MDL

MDM

$\mathrm{Me}$

$\mathrm{mfb}$

MG

$\mathrm{MHb}$

$\mathrm{Mi}$

$\mathrm{ml}$

Mo

MO5

mp

MPA

MPB

MPO

MS

MSO

$\mathrm{mt}$

MTu

MVe

OB

OclB

OclM

Oc2L

Oc2M

Op

opt

Or

ox

$\mathrm{Pa}$

Par

PaS

PC

$\mathrm{Pe}$

PF

Pir

PLCo

PMD

PMV

Pn
Infralimbic cortex

Po

Intermediodorsal $\mathrm{n}$., thalamus

Inf. olive

Interpeduncular $\mathbf{n}$.

Int. plexiform layer, olfactory bulb

Lat. amygdaloid $\mathrm{n}$.

Locus coeruleus

Laterodorsal $\mathbf{n}$, thalamus

I at. hypothalamic a.

Lat. habenula

Lat. hypothalamus

Lat. mammillary $\mathrm{n}$.

Lacunosum moleculare layer, hippocampus

Lat. olfactory tract

Lat. orbital cortex

Lateroposterior n., thalamus

Lat. parabrachial $\mathrm{n}$.

Lat. preoptic a.

Lat. sup. olive

Lat. septal n.

Lat. vestibular $\mathrm{n}$.

Mediodorsal n., thalamus

MD, cent. part

$\mathrm{MD}$, lat. part

MD, med. part

Med. amygdaloid $\mathbf{n}$.

Med. forebrain bundle

Med. geniculate n.

Med. habenula

Mitral cell layer (olfactory bulb)

Med. lemniscus

Molecular layer, dentate gyrus

Motor trigeminal $\mathbf{n}$.

Mammillary peduncle

Med. preoptic a.

Med. parabrachial $n$.

Med. preoptic $n$.

Med. septum

Med. sup. olive

Mammillothalamic tract

Med. tuberal $\mathrm{n}$.

Med. vestibular $\mathrm{n}$.

Olfactory bulb

Occipital cortex, binocular (primary) part

Occipital cortex, monocular (primary) part

Occipital cortex, lat. part

Occipital cortex, med. part

Optic n. layer, sup. colliculus

Optic tract

Stratum oriens (hippocampus)

Optic chiasm

Paraventricular n., hypothalamus

Parietal cortex

Parasubiculum

Paracentral n., thalamus

Periventricular n., hypothalamus

Parafascicular n., thalamus

Piriform cortex

Posterolateral cortical amyg. $n$.

Premammillary n., dors. part

Premammillary n., vent. part

Pontine $\mathrm{n}$.

PT

py

Py

R

Rt

$\mathrm{S}$

SI

st

TC

$\mathrm{Te}$

TT

$\mathrm{Tu}$

$\mathrm{Tz}$

ZI
PRh

PrS

PVA

PVP

$\mathrm{Rad}$

$\mathrm{Re}$

RS

$\mathrm{SC}$

SCh

scp

SHy

SIm

sm

SNC

SNR

Sol

sox

Sp5

SPF

SpVe

Sth

SuG

SuM

SuVe

VDB

VL

VLG

VLL

VM

VMH

VP

VPL

VPM

VTA

\section{References}

Akers R., and A. Routtenberg (1985) Protein kinase C phosphorylates a $47 \mathrm{Mr}$ protein $(\mathrm{F} 1)$ directly related to synaptic plasticity. Brain Res. 334: $147-151$.

Aloyo, V. J., H. Zwiers, and W. H. Gispen (1982) B-50 protein kinase and kinase $C$ in rat brain. Prog. Brain Res. 56: 303-315.

Andrezik, J. A., and A. J. Beitz (1985) Reticular formation, central gray and related tegmental nuclei. In The Rat Nervous System, vol. 2, G. Paxinos, ed., pp. 1-28, Academic, New York.

Armstrong, W. E. (1985) Hypothalamic supraoptic and paraventricular nuclei. In The Rat Nervous System, vol. 1, G. Paxinos, ed., pp. 119-128, Academic, New York.

Bayer, S. A. (1985) Hippocampal region. In The Rat Nervous System, vol. 1, G. Paxinos, ed., pp. 335-352, Academic, New York. 
Benowitz, L. I., and E. R. Lewis (1983) Increased transport of 4449,000 dalton acidic proteins during regeneration of the goldfish optic nerve: A 2-dimensional gel analysis. J. Neurosci. 3: 2153-2163.

Benowitz, L. I., and A. Routtenberg (1987) A membrane phosphoprotein associated with neural development, axonal regeneration, phospholipid metabolism, and synaptic plasticity. Trends Neurosci. (in press).

Benowitz, L. I., and J. T. Schmidt (1987) Activity-dependent sharpening of the regenerating retinotectal projection in goldfish: Relationship to the expression of growth-associated proteins. Brain Res. 417: 118-126.

Benowitz, L. I., V. E. Shashoua, and M. Yoon (1981) Specific changes in rapidly transported proteins during regeneration of the goldfish optic nerve. J. Neurosci. 1: 300-307.

Benowitz, L. I., N. I. Perrone-Bizzozero, and S. P. Finklestein (1987) Molecular properties of the growth-associated protein GAP/B-50. J. Neurochem. 48: 1640-1647.

Bleier, R., and W. Byrne (1985) Septum and hypothalamus. In The Rat Nervous System, vol. 1, G. Paxinos, ed., pp. 87-116, Academic, New York.

Bystrzycka, E. K., and B. S. Nail (1985) Brainstem nuclei associated with respiratory, cardiovascular and other autonomic functions. In The Rat Nervous System, vol. 2, G. Paxinos, ed., pp. 95-110, Academic, New York.

De Graan, P. N. E., C. O. M. Van Hooff, B. C. Tilly, A. B. Oestreicher, P. Schotman, and W. H. Gispen (1985) Phosphoprotein B-50 in nerve growth cones from fetal rat brain. Neurosci. Lett. 61: 235-241.

De Olmos, J., G. F. Alheid, and C. A. Beltramino (1985) Amygdala In The Rat Nervous System, vol. 1, G. Paxinos, ed., pp. 223-334, Academic, New York.

Faull, R. L. M., and W. R. Mehler (1985) Thalamus. In The Rat Nervous System, vol. 1, G. Paxinos, ed., pp. 129-168, Academic, New York.

Freeman, J. A., S. Bock, M. Deaton, B. McGuire, J. J. Norden, and G. J. Snipes (1986) Axonal and glial proteins associated with development and response to injury in the rat and goldfish optic nerve. Exp. Brain Res. (Suppl.) 13: 34-47.

Gispen, W. H., J. L. M. Leunissen, A. B. Oestreicher, A. J. Verkleij, and $\mathrm{H}$. Zwiers (1985) Presynaptic localization of B-50 phosphoprotein: The ACTH-sensitive protein kinase $\mathrm{C}$ substrate involved in rat brain phosphoinositide metabolism. Brain Res. 328: 381-385.

Goldstein, L. S. B., R. A. Laymon, and J. R. MacIntosh (1986) A microtubule-associated protein in Drosophila melanogaster: Identification, characterization, and isolation of coding sequences. J. Cell Biol. 102: 2076-2087.

Heimer, L., G. F. Alheid, and L. Zaborsky (1985) Basal ganglia. In The Rat Nervous System, vol. 1, G. Paxinos, ed., pp. 37-86, Academic, New York.

Hsu, S., L. Raine, and H. Fanger (1981) Use of avidin-biotin complex (ABC) in immunoperoxidase techniques: A comparison between ABC and unlabeled antibody (PAP) procedures. J. Histochem. Cytochem. 29: $577-580$.

Jacobson, R. D., I. Virág, and J. H. P. Skene (1986) A protein associated with axon growth, GAP-43, is widely distributed and developmentally regulated in rat CNS. J. Neurosci. 6: 1843-1855.

Jolles, J., H. Zwiers, C. J. van Dongen, P. Schotman, K. W. A. Wirtz, and W.H. Gispen (1980) Modulation of brain polyphosphoinositide metabolism by ACTH-sensitive protein phosphorylation. Nature 286 : 623-625.

Kalil, K., and J. H. P. Skene (1986) Elevated synthesis of an axonally transported protein correlates with axon outgrowth in normal and injured pyramidal tracts. J. Neurosci. 6: 2563-2570.

Katz, F., L. Ellis, and K. H. Pfenninger (1985) Nerve growth cones isolated from fetal rat brain. III. Calcium-dependent protein phosphorylation. J. Neurosci. 5: 1402-1411.

Knecht, D. A., and R. L. Diamond (1984) Visualization of antigenic proteins on Western blots. Anal. Biochem. 136: 180-184.

Kristjansson, G. I., H. Zwiers, A. B. Oestreicher, and W. H. Gispen (1982) Evidence that the synaptic phosphoprotein B-50 is localized exclusively in nerve tissue. J. Neurochem. 39: 371-378.

Loughlin, S. E., and J. H. Fallon (1985) Locus coeruleus. In The Rat Nervous System, vol. 2, G. Paxinos, ed., pp. 79-94, Academic, New York.

Lovinger, D. M., R. F. Akers, R. B. Nelson, C. A. Barnes, B. L. Mcnaughton, and A. Routtenberg (1985) A selective increase in phos- phorylation of protein $F 1$, a protein kinase $C$ substrate, directly related to three day growth of long term synaptic enhancement. Brain Res. 343: 137-143.

MacLean, P. D. (1985) Fiber systems of the forebrain. In The Rat Central Nervous System, vol. 1, G. Paxinos, ed., pp. 417-440, Academic, New York.

Malenka, R. C., D. V. Madison, and R. A. Nicoll (1986) Potentiation of synaptic transmission in the hippocampus by phorbol esters. Nature 321: 175-177.

Meiri, K. F., K. H. Pfenninger, and M. B. Willard (1986) Growthassociated protein, GAP-43, a polypeptide that is induced when neurons extend axons, is a component of growth cones and corresponds to pp46, a major polypeptide of a subcellular fraction enriched in growth cones. Proc. Natl. Acad. Sci. USA 83: 3537-3541.

Moya, K. L., L. I. Benowitz, S. Jhaveri, and G. E. Schneider (1987) Enhanced visualization of axonally transported proteins in the immature CNS by suppression of systemic labeling. Dev. Brain Res. 31: 183-191.

Nelson, R., and A. Routtenberg (1985) Characterization of protein Fl ( $47 \mathrm{kDa}, 4.5 \mathrm{pI}$ ): A kinase C substrate directly related to neural plasticity. Exp. Neurol. 89: 213-224.

Nelson, R. B., A. Routtenberg, C. Hyman, and K. H. Pfenninger (1985) A phosphoprotein $(F 1)$ directly related to neural plasticity in adult rat brain may be identical to a major growth cone membrane protein (pp46). Neurosci. Abstr. 11: 927.

Neve, R. L., N. I. Perrone-Bizzozero, S. Finklestein, H. Zwiers, E. Bird, D. M. Kurnit, and L. I. Benowitz (1987) The neuronal growthassociated protein GAP-43 (B-50, F1): Use of CDNAs to show the neuronal specificity, developmental regulation and regional distribution of the human and rat mRNAs. Molec. Brain Res. 2: 177-183.

Nishizuka, Y. (1986) Studies and perspectives of protein kinase C. Science 233: 305-312

Oestreicher, A. B., and W. H. Gispen (1986) Comparison of the immunocytochemical distribution of the phosphoprotein B-50 in the cerebellum and hippocampus of immature and adult rat brain. Brain Res. 375: 267-269.

Oestreicher, A. B., H. Zwiers, P. Schotman, and W. H. Gispen (1981) Immunohistochemical localization of a phosphoprotein (B-50) isolated from rat brain synaptosomal plasma membranes. Brain Res. Bull. 6: 145-153.

Oestreicher, A. B., C. J. Van Dongen, H. Zwiers, and W. H. Gispen (1983) Affinity-purified anti-B-50 protein antibody: Interference with the function of the phosphoprotein B-50 in synaptic plasma membranes. J. Neurochem. 41: 331-340.

Oestreicher, A. B., L. V. Dekker, and W. H. Gispen (1986) A radioimmunoassay (RIA) for the phosphoprotein B-50: Distribution in rat brain. J. Neurochem. 46: 1366-1369.

Paxinos, G., and C. Watson (1986) The Rat Brain in Stereotaxic Coordinates, Academic, New York.

Perrone-Bizzozero, N. I., S. P. Finklestein, and L. I. Benowitz (1986) Synthesis of a growth-associated protein by embryonic rat cerebrocortical neurons in vitro. J. Neurosci. 6: 3721-3730.

Perry, G. W., D. W. Burmeister, and B. Grafstein (1987) Fast axonally transported proteins in regenerating goldfish optic nerve. J. Neurosci. 7: 792-806

Pfenninger, K H. (1986) Of nerve growth cones, leukocytes and memory: Second messenger systems and growth-regulated proteins. Trends Neurosci. 9: 562-564.

Routtenberg, A. (1985) Phosphoprotein regulation of memory formation: Enhancement and control of synaptic plasticity by protein kinase C and protein F1. Ann. NY Acad. Sci. 444: 203-211.

Routtenberg, A., and Y. H. Ehrlich (1974) Endogenous phosphorylation of four cerebral cortical membrane proteins: Role of cyclic nucleotides, ATP and divalent cations. Brain Res. 92: 415-430.

Sefton, A. J., and B. Dreher (1985) Visual system. In The Rat Nervous System, vol. 1, G. Paxinos, ed., pp. 169-222, Academic, New York.

Skene, J. H. P. (1984) Growth-associated proteins and the curious dichotomies of nerve regeneration. Cell 37: 697-700.

Skene, J. H. P., and M. Willard (1981a) Changes in axonally transported proteins during axon regeneration in toad retinal ganglion cells. J. Cell Biol 89: 86-95.

Skene, J. H. P., and M. Willard (1981b) Axonally transported proteins associated with growth in rabbit central and peripheral nervous system. J. Cell Biol. 89: 96-103.

Skene, J. H. P., R. D. Jacobson, G. J. Snipes, C. B. McGuire, J. J. 
Norden, and J. A. Freeman (1986) A protein induced during nerve growth (GAP-43) is a major component of growth cone membranes. Science 233: 783-786.

Switzer, R. C., J. De Olmos, and L. Heimer (1985) Olfactory system. In The Rat Nervous System, vol. 1, G. Paxinos, ed., pp. 1-32, Academic, New York.

Tork, I. (1985) Raphe nuclei and serotonin containing systems. In The Rat Nervous System, vol. 2, G. Paxinos, ed., pp. 43-78, Academic, New York.

Van Dongen, C. J., H. Zwiers, P. N. E. De Graan, and W. H. Gispen (1985) Modulation of the activity of purified phosphatidylinositol4-phosphate kinase by phosphorylated and dephosphorylated B-50 protein. Biochem. Biophys. Res. Commun. 128: 1219-1227.

Worley, P. F., J. M. Baraban, and S. Snyder (1986) Heterogeneous localization of protein kinase $\mathrm{C}$ in rat brain: Autoradiographic analysis of phorbol ester receptor binding. J. Neurosci. 6: 199-207.

Zilles, K., and A. Wree (1985) Cortex: Areal and laminar structure. In The Rat Nervous System, vol. 1, G. Paxinos, ed., pp. 375-416, Academic, New York.

Zwiers, H., H D. Veldhuis, P. Schotman, and W. H. Gispen (1976)
ACTH, cyclic nucleotides, and brain protein phosphorylation in vitro. Neurochem. Res. 1: 669-677.

Zwiers, H., V. M. Wiegant, P. Schotman, and W. H. Gispen (1978) ACTH-induced inhibition of endogenous rat brain protein phosphorylation in vitro: Structure-activity study. Neurochem. Res. 3: 455463.

Zwiers, H., P. Schotman, and W. H. Gispen (1980) Purification and some characteristics of an ACTH-sensitive protein kinase and its substrate protein in rat brain membranes. J. Neurochem. 34: 16891699.

Zwiers, H., J. Verhaagen, C. J. Van Dongen, P. N. E. De Graan, and W. H. Gispen (1985) Resolution of rat brain synaptic phosphoprotein B-50 into multiple forms by two-dimensional electrophoresis: Evidence for multisite phosphorylation. J. Ncurochem. 44: 10831090.

Zwiers, H., A. B. Oestreicher, M. A. Bisby, P. N. E. De Graan, and W. H. Gispen (1987) Protein kinase C substrate B-50 in adult and developing rat brain is identical to axonally-transported GAP-43 in regenerating peripheral rat nerve. In Axonal Transport, R. A. Smith and M. Bisby, eds., pp. 421-433, Liss, New York. 